\title{
"To laugh or not to laugh": Understandings of the appropriateness of humour and joking in the workplace
}

\author{
Brian D. Vivona, Ed.D. \\ Governors State University, Illinois, United States of America
}

\begin{abstract}
In order for joking to actually have a function in the workplace, it must have a forum. There are many pieces of empirical research on humour in the workplace, however the notion of the appropriateness of joking behaviour is often overlooked. The time, place, and circumstances of when joking does or does not occur is related to the situated and contextual nature of humour and issues linked to the private/public domain often will delineate when humour is acceptable or not. When, where, and, most importantly, the permission to joke is important to the understanding of the functional nature of humour. In order to gain an understating of how workers understand the notion of appropriateness, a qualitative study of a very unusual group of workers, crime scene investigators, was undertaken. Tacit personal and organisational belief systems related to culture and learned normative behaviours help determine when and where joking is allowed or forbidden.
\end{abstract}

Keywords: workplace culture; tacit knowledge; appropriateness of joking.

\section{Introduction}

Humour, joking, and shared laughter are basic and fundamental parts of human interaction, especially in the workplace (Morreall 2008). The definitions of humour are many; however, for the context of this research, humour is considered an "emotional response of mirth in a social context that is elicited by a perception of playful incongruity and is expressed through smiling 
and laughter" (Martin 2007: 10). Joking is the overt communication of humour formed through social interaction, culture and context. Examples of joking are witty stories, banter, puns, and telling jokes.

Research has shown that humour has numerous psychological and social benefits. Accounts of these benefits have led several researchers and practitioners to bring humour into social, educational, health, and work settings (for examples, see Wallinger 1997; Klein 1998; Hudson 2001; McGhee 2010). Not surprisingly, workers believe their workplaces should be enjoyable (Romero \& Pescosolido 2008). Practitioner publications such as Forbes, Outside Magazine, Fast Company, regularly present their own lists and evaluations of "the best places to work". Fun, relaxed, and positive social workplaces consistently place high on these non-scientific evaluations.

Workplace humour has been studied from numerous perspectives and theoretical frameworks, such as humour and gender roles (Collinson 1988), socialisation (Vinton 1989), social interaction (Gardenswartz \& Rowe 1994), functionalism (Holmes \& Marra 2002), normative theory of groups (Romero \& Pescosolido 2008), and communication (Schnurr 2008). These and many other studies have explored the contextual, social, organisational, and functional nuances of humour in the workplace. However, they fail to adequately address an important construct: How do workers determine appropriateness of joking behaviour in specific work contexts?

This study examines tacit understandings and learned behavioural norms within the workplace, and how those understandings influence workers' judgments regarding the appropriateness of joking behaviour. Participants shared their perspectives through retrospective narrative accounts on the appropriateness of joking within various workplace settings. These perspectives were based on their personal beliefs and practices regarding when they engaged or did not engage in joking behaviour.

This research is framed within the construct of organisational culture. Organisational culture may be considered from several perspectives, for example: deeply held assumptions, meanings, and beliefs (Martin 2007); common experiences and shared meanings (Weick 1995); memory (Alavi \& Tiwana 2003); and the language of interaction between individuals of the same occupation (Elkjaer 2003). From each of these perspectives, members share understandings of events and behaviours. Organisations have embedded learning processes (Dibella 2003), and through these processes they become familiar with what is normative for their culture and what is not.

Humour and joking can often provide an insight into the organisational culture of a workplace. A culture often grows organically from a group's history, organisation, and social relationships; joking and humour can help create and sustain an organisation's culture, especially within teams (Dewey \& Carter 2003). Consistent with culture as shared meaning, language and experience, an organisation's values, norms, and certain behavioural outcomes expected from its membership can often be communicated through humour (Romero \& Cruthirds 2006). The culture of the workplace may provide the worker with mental models of when, where, and how joking is accepted or unacceptable. 
European Journal of Humour Research 2 (1)

\section{Workplace humour}

Humour exists in most workplaces. As Westwood \& Rhodes (2007: 5) explain, "[h]umour and comedy are pervasive, entrenched, and highly meaningful aspects of human experience, and they are as significant in organisational and work contexts as they are in any other domain of human activity." Much of the research, but of course not all, regarding humour in the workplace resides within a functionalist perspective. Functional interpretations of joking behaviour view humour in terms of the social functions humour often plays within a social context. This functionalist approach to humour is common when studying humour within groups (Kuipers 2008). Most of the workplace humour research to follow examined humour practices and interpreted those practices from various frameworks.

Workplace humour has been examined in several empirical studies that highlight various work settings. Authors have discussed how humour is used to control coworkers' performance and reduce inequalities (Collinson 1988), emphasise power imbalances, and challenge status hierarchies (Collinson 2002; Taylor \& Bain 2003). Lynch (2010) researched the use of humour by kitchen workers and discovered an array of complex processes through which the social organisation is (re)produced and transformed through its members' everyday in-group humour. In a study of information technology workers, Plester \& Sayers (2007) discovered joking behaviour described as "banter" that was used to facilitate synergy and functioning in work groups.

Humour in work environments is seldom neutral or trivial (Barsoux 1996); on the contrary, it is frequently purposeful (Vinton 1989; Porcu 2005). Its purposes may include defining the roles of various employees at different levels of an organisation (Duncan et al. 1990) as well as influencing positive group effectiveness and identity (Romero \& Pescosolido 2008). Humour also plays a role in how workers select and retain interpretations of work events. Therefore, humour is used by workers to make sense of organisational identities and work experiences (Tracy \& Scott 2006).

Humour can be used to establish cohesion within organisational ranks, or it can be applied as a form of resistance. Holmes \& Marra (2002) determined that subordinates use humour in formal work settings as a means to challenge and criticise their superiors. Joking behaviour can be part of a subversive movement against the organisation; however, the comedy or joke "cannot on its own subvert established order" (Westwood 2004: 777). A joke in isolation is neither supportive or subversive nor positive or negative in organisational contexts. Joking behaviours develop and evolve as part of the organisational history.

\section{Joking and organisational culture}

Functions of humour can also be indicative of the organisation's and the occupation's culture. Humour can provide a glimpse into the group's cultural characteristics (Vinton 1989; Holmes \& Marra 2002; Fine \& De Soucey 2005). For example, Plester \& Orams (2008) determined that the types and functions of humour used within three IT companies can be reflective of the industry in general. In settings quite different from these IT companies, Fine \& De Soucey (2005) described unique joking behaviour embedded in the culture of both mushroom collectors and meteorologists. 
A work context that provides an excellent backdrop for understanding humour as a function of organisational culture resides within occupations that perform what is referred to as dirty work. Workers who at times must perform dirty work (i.e. those jobs considered to be physically, morally, or socially tainted, such as garbage collectors, funeral and morgue workers, exterminators, mine workers) have been shown to develop protections that provide identity and meaning to the work to the point that it becomes a source of pride and engagement. The strong culture of many of these dirty work occupations also provides resources to help reframe and refocus the meaning of dirty work, to the point where the work is embraced (Ashforth \& Kreiner 1999). Ashforth et al. (2007) found that humour was a tactic used by various workers who perform dirty work. These types of workers acknowledged the tainted nature of their work and applied humour to relieve tension, demarcate group inclusion, and strengthen group cohesion.

Humour as a research construct is very dependent on its context; the development of personal and occupational identity will influence the individual's production, purposefulness, and interpretation of joking behaviour. What is funny to one socioethnic group or certain individuals may not be to another. For example, aggressive humour that is racist or sexist may alienate people within the organisation, undermine relationships, and create a hostile work environment (Goodman 1983; Hughes 2002; Romero \& Cruthirds 2006). Although such humour may often be considered offensive and inappropriate, yet these forms of humour exist in workplaces and continue to surface in lawsuits against places of employment.

The literature on the relationship between humour and organisational culture also reveals that the behavioural norms of an organisation can be located in the humorous stories and anecdotes passed from one worker to another (Romero \& Cruthirds 2006). The passing of these stories allows new members of an organisation to begin to understand more about how joking and work are connected within the organisation, they experience examples of the situated nature of humour and when it is allowed or forbidden (Meyer 1997). Workplaces have their own unique context and culture, and what is revered in one context may be vilified in another. How workers begin to interpret these encounters is through tacit and learned experiences.

\section{Tacit and learned understanding of behaviour norms}

According to Eraut (2000), the distinction between formal and non-formal learning is the intention to learn. He explains that tacit learning is not part of a deliberate process; it is more related to memories and linkages from one's past. Memories of episodes are not consciously available to workers in the form of a "tacit knowledge base, which enables future action" (Eraut 2000: 116). An example used by Eraut is riding a bicycle: individuals may be able to pinpoint when and where they learned to ride; however, they would probably not be

able to describe critical aspects of the knowledge gained, such as rapid responses to a sense of impending imbalance, while other relevant knowledge, such as the steadying effect of the gyroscopic motion of the wheels, would almost certainly never be acquired.

(Eraut 2000: 118)

People bring their lifelong experiences to their workplace; during the course of their lived experiences they develop a personal belief system that guides many of their behaviours. 
Individuals may be able to explicitly describe what they had learned from some experiences; however, in other instances they may be unable to articulate how or where they learned a behaviour or belief.

Whereas learned understandings of behaviour in the workplace can occur through experience, learning results from the reflection upon that experience (Brookfield 1998). This explicit activity can result in a process of change in individuals and shared thoughts and actions (Vera \& Crossan 2005). Images of experiences, dialogue among workers, and shared understandings result in a construction of what behaviours are acceptable and not acceptable. Within these shared understandings, perspectives about humour applications can reside.

\section{Methods}

Humour is a complex phenomenon, and one of the strengths of the qualitative research approach used in this study is its ability to capture complex textual descriptions of how people experience a particular research problem (Mack et al. 2005). Qualitative methods permit the researcher to manage the fieldwork without being limited by predetermined categories of analysis, and allow the researcher to study the selected topic in depth and detail (Patton 1990).

\subsection{Research participants}

Law enforcement and those tasked with investigating serious crimes (e.g. murder and kidnapping) possess strong occupational and organisational cultures. The criminal investigation of homicide and violent crime requires trained and experienced staff, proper investigative procedures, and thorough analytical processes. Many small to middle-sized police agencies have joined in collaborative efforts to solve murders. Agencies located in the suburban areas of major cities, such as St. Louis and Chicago, have formed multijurisdictional task forces whose mission is to provide experienced and professional investigative and forensic support to member agencies involved in investigating major incidents.

This work context was selected for several reasons. As previously noted, these groups have strong cultural and behavioural norms that may provide insight into tacit and learned understanding of humour's appropriateness. The interaction and communicative strategies used during high profile investigations provide opportunities for these workers to engage in humour and joking behaviour. Crime scene investigators (CSIs) work together at processing a scene, and this collaboration becomes a working alliance. This collaboration is also socially significant, especially within the context of high-stress tasks such as processing murder scenes. These social interactions provide opportunities for behaviours to be modelled, integrated into the work culture, and understood amongst the workers.

This work may also be considered within the realm of dirty work as described by Ashforth \& Kreiner (1999) (see section 3). Crime scene investigators experience death in a more detailed manner than other law enforcement officers: "They confront extraordinarily disintegrative visual and olfactory images of death, but they experience tactile images as well" (Henry 2004: 178). Karlsson \& Christianson (2003) determined that officers who have physical contact with the dead often have strong tactile memories, and the experiences often remain in their memories in the 
form of various physical sensations. CSIs regularly experience the cumulative effects of psychologically stressful environmental factors. These factors include decomposing corpses, blood spatter, and mangled bodies.

Lastly, I had access to this population because of my insider status as a former CSI and task force officer. This insider status provided the opportunity to study a hard to access population: police officers in general are often hesitant to reveal themselves to outsiders; the police culture is very strong, influential, and holds a commitment to law enforcement officers above all else (Woody 2005). Patton (1999) also discussed personal connections with the people and topic as being an important aspect of the researcher's credibility. From this perspective, my insiderness provided the access I needed to conduct this study.

For this study, I interviewed 14 CSIs from four separate municipal-level major case squads and one federal Emergency Response Team (ERT). The sample included ten males and four females, ages ranged from 31-65, years of crime scene experience ranged from 6-37, and the average length of crime scene experience was 13.7 years. Thirteen participants were current CSIs; one had retired several years before.

\subsection{Data collection and analysis}

The main data source was semi-structured in-depth interviews. Narratives from participants provided data regarding the use of humour and joking in this work setting. These narratives described the content and context of when and where joking was and was not deemed appropriate. Interviews were conducted face-to-face at a site of the participant's choosing, were digitally recorded, and transcribed by the author. One interview had to be cut short because of a participant's unexpected work issue. The interviews lasted between 45 minutes and 1.5 hours. All participants were assigned pseudonyms.

There are several issues regarding relying solely on the interview as a method of data collection. While this work is in no way meant to be viewed as a primer on qualitative research, some of the issues are worth noting. While the researcher's lens does influence the questions asked, the semi-structured interview provides the participant with a high degree of freedom within their response. While the structure of the interviews maintains alignment with the goals of the research, there is still opportunity to follow up on responses in whatever areas and direction the responses require.

A potential problem with the interview format is the construct of social desirability bias. This is when the participant wishes to please the interviewer by providing responses the participant believes to be desired (Grimm 2010). These responses may not be representative of their true feelings, especially in this research setting where several of the participants and I had a previous working relationship.

In the original research proposal, participant observation was requested to be an additional source of data. However, the Institutional Review Board (IRB) determined that such a source of data would be troubling from several perspectives. First, the IRB had questions on gaining permission for observation. Individual officers, the various agencies, task forces, and prosecutors were all stakeholders. The IRB could not determine which (or all) stakeholders could give permission. Secondly, the IRB felt that participant observation during an ongoing criminal investigation could compromise the due process of law. For example, a question posed was if my 
field notes would be discoverable (discovery is a process in the pretrial phase of courts of law in the United States - all documents relating to the investigation, including officers' notes and reports, must be produced and given to the defence) during the trial process; if so, this could affect the trial as well as compromise the confidentiality of participants. It is acknowledged that participant observation would have provided additional data sources that would strengthen the trustworthiness of the data; however, the challenges of such data collection led me to eliminate that request from the proposal.

I analysed the data using the constant-comparative method of qualitative analysis (Glaser \& Strauss 1967). Interview transcripts were analysed multiple times. After transcription, each interview was reviewed, comparing similarity of words, experiences, and ideas within the interview. Each passage of each interview was studied to determine exactly what was said and to affix a label or code to each passage. The collection of these labels or codes is the initial process of conceptualisation of themes that emerge from the data (Boeije 2002).

After I had completed several interviews, I began comparing them. The categories and transcripts were scrutinised, rearranging, combining, and renaming initial themes. The comparison displayed whether concepts were common across interviews. Through this iterative process, I developed a set of themes that addressed the question of determining the appropriateness of using joking in this work setting.

\subsection{Positionality - My role with this research}

Positionality pertains to the relationship of the researcher with the phenomenon that is being examined. My researcher role as a former police officer conducting research on other police officers must be addressed. Many of my attributes and characteristics intersect with those of the research participants. Several perspectives regarding insider status can be found throughout the literature. I chose to research a group to which I had belonged, and the participants chose to allow me to study them. In addition to the issue described above of police officers not wishing to reveal themselves to outsiders, the nature of the work (i.e. professionals involved in criminal investigations) makes accessibility to this research population difficult. Insiderness can be advantageous because these workers may be more open to discussing their trade with "one of their own."

Credibility of the researcher in the eyes of the participants is an important aspect of qualitative research; Patton (1999) described personal connections with the people and topic as being an important aspect of the researcher's credibility. There are also arguments that insiderness is crucial in research because being an outsider limits the understanding of hidden meanings and the ability to reach a deep level of trust with the informant (Haniff 1985). From these perspectives, my insiderness provided the access, trust, and credibility I needed to conduct this study.

An additional point regarding my insiderness is my experience with this phenomenon. I was aware of the existence of humour in this work context. It intrigued me because of the disparate constructs of death and humour coinciding in the same space. Upon reflection, I had an understanding of my own boundaries for using joking behaviour, but wanted to understand how others as individuals and as groups determined what, when, and where humour was allowed or disallowed. 


\subsection{Ethics and representation}

"Given that qualitative research deals with more complex settings, it only follows that our ethical responsibilities will be equally more complex" (Shank 2006: 120). As a qualitative researcher, I was the lens through which data were analysed. The role duality between researcher and former member of this group leads to choices as to what is revealed and how it is interpreted. On the one hand, I shared an occupational identity with the participants; I made assumptions and interpretations of humour from that perspective. On the other hand, some interpretations of humour emerged from my developing understanding of the literature and identity as a researcher. Most likely, the realities of these two roles were divergent in some areas and congruent in others.

Fein et al. (2000) presented what they refer to as the "triple representation problem." They ask researchers to reflect upon how they present themselves, the narrators, and others. For this research, I was required to be sensitive to my own triple representation issue. First, I chose certain accounts and narratives; I presented and selected accounts that only reflect a small portion of these participants' lived experiences. These accounts only represent their experiences with joking in this work context. Second, CSIs revealed themselves and allowed me to report and interpret how they had constructed certain experiences with joking. Finally, some victims of horrible crimes were presented, and these victims and their families had no opportunity to be heard. I do not wish to victimise these people a second time. My intent throughout this process was not to present an agenda or voyeuristic or judgmental account of humour; it was to present how CSIs constructed their experiences with joking in their work.

\section{Results}

Crime scene investigators are often thrust into situations where they have little to no control. These participants spoke of going through garbage dumpsters searching for pieces of dismembered bodies, searching crawlspaces for spent bullets, and following blood trails through the snow, among other difficult tasks. In most of the accounts of these scenarios, joking and laughter were recalled in some portion of the crime scene investigation. The retrospective accounts were consistent with Kuhlman's (1988) research in which joking for some groups seems to relieve stress in situations where control is difficult or not possible.

The time, place, and circumstances of when joking does or does not occur is related to the situated and contextual nature of humour. When, where, and, most importantly, the permission to joke is important to the understanding of the functional nature of humour. The data revealed that the understandings of appropriateness of joking in this setting can be looked at from viewpoints of (1) personal and occupational cultural standards and (2) beliefs, context, and audience.

\subsection{Personal and occupational cultural standards}

Most humour researchers acknowledge that humour is dependent on context. Aligned with this acknowledgment, CSIs show an awareness of the contextual nature of humour and joking. The 
participants made conscious decisions on when and where joking was allowed or not. Morreall (2009: 92) provided a review of the negative ethics of humour. Most of the objections to humour relate to "morally objectionable effects" such as violent, racist, and sexist jokes.

Crime scene investigators bring to their work a set of personal beliefs and standards acquired tacitly over their personal and professional development. Appropriateness of CSIs' joking is related to senses of morality and ethical behaviour. This sense of what is right and wrong are a mix of personal beliefs and normative behaviours of this culture. Many CSIs expressed tremendous empathy for the victims, especially for those who were deemed innocent of any wrongdoings. Sally told me that she feels that her coworkers have clear moral standards:

I think that we are all respectful to the victims... We all have a sense of right and wrong, that line of cracking jokes.

However, the more I spoke to the participants, the more I determined that their personal sense of morality in regard to joking and death varied on a continuum. Religious or spiritual views allowed some of them to regard the body as a mere shell for the person's soul; thus, the soul was gone and therefore a disassociation existed regarding the person and the remains. Frank's perspective displayed this viewpoint:

I have a different perspective; a person has his living spirit, his body is just a vessel that carries his spirit. I disassociate myself from what I see, like a butcher would disassociate himself from the family calf.

Stanley presented a view that would seem almost cruel upon its initial hearing, but upon more thoughtful introspection, he explained himself:

It's going to sound cold, but they are meat, whether you think they've got a soul, a force, whatever, it's gone, they are just meat... But for me, if I didn't know them, I mean, I like to ask the victim's name. Whether you like to believe like the movies they are watching you, I talk to them, I talk to dead people, I like to make a bit of a connection with them.

Stanley's view of the victim is not a contradiction based on his interpretation of the situation. On the one hand, he needs to disassociate himself from the victim in order to perform the sometimes ghastly work. This situation involves what Henry (2004) refers to as the death imprint, intrusive images that evoke negative feelings associated with the death encounter. On the other hand, Stanley's personal belief system forces a need to somehow connect to the victim; the task and his personal beliefs form a paradox.

Within this work culture, CSIs can become acculturated to an almost perverse joy of not being affected by death (Henry 1995). They can also laugh about this cumulative process because this is who they have become. Stanley related an insight about this work culture:

If you were to walk onto a scene you would think our group, as professional as we are, are a bunch of twisted freaks because we can go in there. When I was young I heard the stories of some guy down at the morgue eating a sandwich. I could do that now; it wouldn't affect me, aside from the germs and disease part (laughs). 
Stanley's comment presents an example of behavioural norms learned through work events over time. What may have been shocking (i.e. inappropriate) early in a CSI career begins to be viewed as a routine aspect of the work. The abnormal becomes normalised as these workers gain more experience.

\subsubsection{Permission to joke}

Some participants acknowledged that they had engaged in joking behaviour that could be considered inappropriate, especially if it was separated from the circumstances of the context. However, they explained that the humour was needed to improve a situation. They rationalised that the functions of the joking behaviour trumped its inappropriateness. Eric acknowledged that he reflects on the potential inappropriateness of his workplace humour, but he also acknowledges its critical necessity:

Yes, I apologise; I would feel bad if the wrong people heard it. But for me to do my job the best I can I need to be relaxed; I need to be focused... If I am worked up, I am not going to do the best job... I don't want people to think that you're joking around; you don't care about this person's death. No, we really do, this is a way we keep loose and keep going.

Group members tacitly understand that certain topics are simply off limits; however, some CSIs enjoy pushing those limits and testing their own and each others' boundaries. Bob commented on his sense of boundaries:

I have a very raunchy sense of humour; my guidelines are probably more lax than most people... To be honest, there have been times I've cracked jokes that I look over my shoulder, whoa, I hope I didn't offend anybody.

Westwood \& Johnston (2012) explored how normative controls intrude into an individual's identity; organisations and their behavioural requirements may command inauthentic behaviour. Bob pushes boundaries because that is part of who he is; despite the potential dangers inherent in his sense of humour, he is true to himself. For Morreall (2009), humour involves cognitive as well as practical disengagement. Bob acknowledged his belief that joking is needed in some tragic situations regardless of its perceived or normative level of appropriateness. He disengages from the images he finds shocking for a short time before he can re-engage and perform his professional work at a high level of accuracy.

\subsubsection{Gallows and sick humour}

I was told about certain crime scenes that were so shocking to the human system that even the most seasoned CSI had to take a step back and call upon humour and joking that anyone outside of this occupation would view as vastly inappropriate. Humour that is alternatively referred to as gallows, sick, dark, and/or black humour was described as being used by CSIs. It is not 
commonplace; participants viewed most joking targeted at victims as unprofessional and inappropriate. They seemed to have an emotional blockage to poking fun at the dead.

Gallows or sick humour is a very specific humour style that is often used in very threatening circumstances, situations that are too serious to be funny (Triezenberg 2004). It is a style of humour on the edges of social acceptability (Thorson 1993). Roger provided an example of how this type of humour can emerge at grotesque crime scenes:

I have had my guys make wise-ass cracks about maggots crawling on the body... Those maggots are crawling around and there's always one of my guys orders rice at lunch afterwards, let's eat Chinese today. They are laughing their asses off.

Many who have not been exposed to this sort of work and are looking from the outside in would find some of the comments callous, juvenile, and/or twisted. An additional example is Dan's encounter with a beheading:

The headless body one, when I got to the scene a couple of other officers were there. I was in the backyard about to let myself inside. I took my coat and pulled it over my head and zipped it up, went inside with my arms out and said, "Hey, Hey!".

The participants' accounts are aligned with Carver (1997) and Saroglou \& Anciaux (2004), who explained that people may make fun of what threatens them, and that joking can be a mental disengagement from emotionally troubling or threatening circumstances. The idea that those outside this work culture do not understand the need for joking in this context segues into the next theme, context and audience.

\subsection{Context and audience}

The participants discussed their personal and professional belief systems regarding humour. However, one construct regarding the appropriateness of joking was common to each participant. Related to the above discussion on occupational culture, they believed that those outside this line of work simply cannot understand the need for humour. The audience for humour and joking behaviour is an important factor in its appropriateness. Telling about a humorous circumstance among colleagues and friends may be amusing; however, that same account in front of an audience that does not possess that same frame of reference may not only be unfunny but could potentially be offensive. This finding is consistent with humour literature: "An assessment of the appropriateness of the situation for telling a joke or making a humorous remark is necessary" (Nijholt 2004: 3). Each CSI expressed the need for discretion when engaged in joking. This discretion is needed to prevent the wrong ears from hearing laughter; these wrong ears can belong to family and friends of the victim and the general public.

For these CSIs, they explained that humorous narratives and active joking behaviour should only be shared within the work group. Discretion with workplace humour is a learned skill by CSIs; it is part of the socialisation process as CSIs transition from novice to expert workers. Several CSIs expressed a concern about offending someone and therefore lessening the status of not just themselves but of the group. Stanley commented on this phenomenon: 
Yes, time and place, you have to remember your audience. What we on the team might find funny another might not, they are not in our shoes, they don't do what we do, they don't go where we go, they don't see what we see.

Each CSI expressed an understanding of the pain and suffering victims' families go through. Whether from suicide, homicide, or fatal traffic crash, traumatic death has a much larger and profoundly negative effect on family and loved ones than natural or anticipated death (Stroebe \& Schut 1999; Neimeyer 2001). Frank commented on the importance of this issue:

Humour has its place, but it is also important on major scenes it is kept within the group. You never want someone taking a picture of you laughing at a death scene. Even if it is the most innocent thing on earth, the family will never understand it.

Stanley linked his professionalism with the respect he believes must be given to victims and families:

In death they deserve respect. They are still somebody's family member... It goes back to dignity, give them respect in death. I don't care if he's a piece of shit that committed the offense or the victim. That's being a professional.

As a supervisor, Frank is very concerned about appearing to be unprofessional, and he commented on the importance of his team conveying a professional image:

Most people don't understand humour in this situation. If it's in the privacy of the station or out of the public view, I laugh, but in the back of my mind it's always worrying me that some news organisation is going to have a long distance camera and is going to take a picture of one of my guys laughing at an inappropriate time. You don't want to see a bunch of guys on the cover of the newspaper laughing after three people got murdered.

Ken affirmed the notion that joking needs to be out of the public's view:

The appropriate time is when it's just us, and there is nobody else. Specifically at the crime scene when it's all contained to the confines of our unit, the truck, the scene where it cannot be heard, that's appropriate, anything outside of that is inappropriate.

Most media outlets possess incredible technology; long telephoto lenses and parabolic microphones can see and hear what the CSI is doing from long distances. Keeping prying eyes and ears from the immediate area around a crime scene is nearly impossible. Crime scene investigators are aware of the capabilities of these technologies and the repercussions that would occur if a CSI was perceived to be unprofessional or uncaring by the public. The use of discretion with humour is modelled and directed by experienced CSIs and team supervisors. Inexperienced CSIs are not permitted to learn discretion through trial and error. Frank stated that even though he knows his team understands the dangers of an inappropriate joke, he reminds them to be on their most professional behaviour when in the public eye. 


\subsubsection{Private space}

Joking can take place in private spaces where the CSI is free from prying eyes and ears. Each forensic unit member with whom I spoke has a command vehicle of some type. The primary purpose of these vehicles is to transport the large variety of needed equipment. These vehicles also act as workspace for writing reports, labelling and logging evidence, briefings, and rest breaks. The CSIs spend a great deal of their time in these vehicles, and they are physical spaces wherein much of the joking behaviour occurs. Stanley commented on his team's command vehicle:

It's acknowledged by everyone; even the detectives know when they show up. They are like, wait a minute, can I be allowed in? That's our hallowed ground, that's home base, everybody knows it; they act like guests when they come in. That's our safe zone for us to go decompress, it's kind of nice that it's recognised that we need a safe spot.

Frank actually joked about the nature of the truck and what goes on inside:

Most of it happens in the truck, that way it's out of the public's view and hearing. It's a wonder we haven't all died from some horrible disease, we are in there eating pizza one minute and picking up body parts the next.

The CSI does not have a workplace comparable to workplaces depicted in most humour studies; they do not work in offices, kitchens, shop floors, or other more traditional workspaces. They work in and around various crime scenes. The command vehicle is the closest thing that these CSIs can view as a traditional workplace. It is the only space they have during the course of their work where they sense familiarity and comfort.

\section{Discussion and conclusion}

CSIs give themselves the permission to joke, and they acknowledge its important functions regarding negotiating and managing stress and emotionally challenging situations. For the CSIs of this study, perceived appropriateness of joking regulated the time, place, style, and targets of humorous exchanges. These CSIs exhibited both tacit and learned understandings of the context and content of humour. Appropriateness of joking behaviour for CSIs is very much related to context, and issues linked to the private/public domain often delineates when humour is acceptable or not. The CSIs of this study communicated that those outside this work setting do not understand the need for humour within it, and therefore the CSIs refrain from joking in most public settings. This understanding is learned via experience and acculturation into the work group.

Klein's (1998) research on humour, death, and dying explained that those who do not work in such an arena often do not understand the need for humour. Furthermore, this finding is also congruent with Alexander \& Wells (1991) and McCarroll et al. (1993), who emphasise that workers in these kinds of situations only feel comfortable laughing out of the public's eye. Joking 
and laughing in public could be viewed as unprofessional, uncaring, and/or offensive. Several CSIs explained that they did not wish to be seen joking in public; therefore, CSIs engage in much of their joking in private.

Workspaces influence the structure and culture of people and groups (O'Toole \& Were 2008). Such "organizational spaces are not empty containers for work; they influence what is going on inside" (Bakke \& Bean 2006: 53). Stanley refers to his command vehicle as "hallowed ground"; his perspective of the physical space of the vehicle is important to how he shares experiences and meaning with his co-workers. These private spaces provide the safety in where the true self can be expressed (Collinson 1988).

A potential danger of this private workplace is the lack of organisational control over behaviour. Organisations and leadership do have an interest to exert some control over certain conduct such as sexist and racist humour (Westwood 2013); law enforcement organisations typically exert control over conduct and behaviour via strict policy, procedures and supervision. Despite such attempts to control behaviour, there are times within their private space that joking, normally off limits, does occur.

One of the limitations of this research is the male dominated sample. The sample was representative of the United States law enforcement population, which is male-dominated. However, research has shown that the types of humour used in same-sex and mixed-sex groups are different (Robinson \& Smith-Lovin 2001). Further, Robinson \& Smith-Lovin (2001), Crawford (2002), and Lampert \& Ervin-Tripp (2006) found the various dynamics of mixedgender humour in work settings may bring a mix of tension, interpretation of joking, and dynamics of gender differences. An area of further research should focus on the participation in or toleration of potentially offensive, or at least, inappropriate humour between mixed-gender groups.

Some of the study participants acknowledged that outsiders may think that joking in public contexts is inappropriate; however, several noted that joking helped them to relax in order to perform this critically important job. The body of knowledge on humour and stress reduction is clear on this point (see Martin \& Lefcourt 1983; Lefcourt 2001; Abel \& Maxwell 2002; Moran \& Hughes 2006; Martin 2007; Cann \& Etzel 2008). The CSIs of this study communicated that engaging in joking outside of the public's view prevented outsiders from making misinformed judgments about the intent of such joking behaviour.

Common to the participants' belief systems was the tacit understanding that joking behaviour should not target the victim. Different CSIs spoke of various reasons for this demarcation, some moral, others religious, and some a sense of professionalism. Their idea of what is moral or ethical is something they develop over their personal and professional lives. Of the CSIs I spoke to, the more experienced ones seemed to have a more relaxed perspective on what was or was not appropriate. Inexperienced CSIs needed a greater filter; the more experienced CSIs felt freer to communicate their thoughts. People become more familiar and comfortable with their work and workplace culture as they gain experience. What may have been shocking early in a CSI career becomes normalised as these workers gain more experience. In this context, a joking behaviour that may have been shocking for a newer CSI has less of an impact on seasoned CSIs; they have become hardened in many ways. What they see, what they hear, and what they joke about no longer surprises them. This evolution is part of the learned understanding that results from working cases and being part of this kind of work group. 
Based on the findings of this study, further research is warranted. We have much to learn about how workers make judgments about appropriateness of workplace humour. Given that humour is inextricably woven into the context of workplaces, additional research is needed that examines humour applications in a wide array of occupations. Research is needed regarding the cues that inform the joking behaviour of workers. The continuum of public to private space and how this delineation influences joking is also relatively unexplored. What cues guide their decisions on discretion with humour? Furthermore, research on humour applications in various occupational settings can help us better understand how workers establish parameters for appropriateness of humour.

\section{References}

Alexander, D. A. \& Wells, A. (1991). 'Reactions of police officers to body-handling after a major disaster: A before and after comparison'. British Journal of Psychiatry 159, pp. 547-555.

Alavi, M. \& Tiwana, A. (2003). 'Knowledge management: The information technology dimension', in Easterby-Smith, M. \& Lyles, M. A. (eds.), The Blackwell Handbook of Organizational Learning and Knowledge Management, Malden/Oxford/Melbourne/Berlin: Blackwell, pp. 104-21.

Ashforth, B. E. \& Kreiner, G. E. (1999). 'How can you do it?: Dirty work and the challenge of constructing a positive identity'. The Academy of Management Review 24 (3), pp. 413-434.

Ashforth, B. E., Kreiner, G. E., Clark, M. A. \& Fugate, M. (2007). 'Normalising dirty work: Managerial tactics for countering occupational taint'. Academy of Management Journal 50 (1), pp. 149-174.

Bakke, J. W. \& Bean, C. J. (2006). 'The materiality of sensemaking'. Tamara Journal for Critical Organization Inquiry 5 (3), pp. 51-69.

Barsoux, J. L. (1996). 'Why organisations need humour'. European Management Journal 14 (5), pp. 500-508.

Brookfield, S. (1998). 'Against naive romanticism: From celebration to the critical analysis of experience'. Studies in Continuing Education 20 (2), pp. 127-142.

Boeije, H. (2002). 'A purposeful approach to the constant comparative method in the analysis of qualitative interviews'. Quality and Quantity 36 (4), pp. 391-409.

Carver, C. S. (1997). 'You want to measure coping but your protocol's too long: Consider the brief cope'. International Journal of Behavioural Medicine 4 (1), pp. 92-100.

Collinson, D. L. (1988). 'Engineering humour: Masculinity, joking, and conflict in shop-floor relations'. Organisation Studies 9 (2), pp. 181-199.

Collinson, D. L. (2002). 'Managing humour'. Journal of Management Studies 39, pp. 269-288.

Crawford, M. (2003). 'Gender and humour in social context'. Journal of Pragmatics 35 (9), pp. $1413-1430$.

Dewey, J. D. \& Carter, T. J. (2003). 'Exploring the future of HRD: The first future search conference for a profession'. Advances in Developing Human Resources 5 (3), pp. 245-256.

DiBella, A. J. (2003). 'Organisations as learning portfolios', in Easterby-Smith, M. \& Lyles, M. A. (eds.), The Blackwell Handbook of Organizational Learning and Knowledge Management, Malden/Oxford/Melbourne/Berlin: Blackwell, pp. 145-160.

Duncan, W. J., Smeltzer, L. R. \& Leap, T. L. (1990). 'Humour and work: Applications to 
management'. Journal of Management 16 (2), pp. 255-278.

Elkjaer, B. (2003). 'Organisational learning with a pragmatic slant'. International Journal of Lifelong Education 22 (5), pp. 481-494.

Eraut, M. (2000). 'Non-formal learning and tacit knowledge in professional work'. British Journal of Educational Psychology 70 (1), pp. 113-136.

Fine, G. A. \& De Soucey, M. (2005). 'Joking cultures: Humor themes as social regulation in group life'. Humor: International Journal of Humor Research 18 (1), pp. 1-22.

Fine, M., Weis, L., Weseen, S., \& Wong, L. (2000). 'For whom. Qualitative research, representations, and social responsibilities', in Denzin, N. K. \& Lincoln, Y. S. (eds.), Handbook of Qualitative Research, 2, Thousand Oaks, CA: Sage, pp. 107-131.

Gardenswartz, L. \& Rowe, A. (1994). Diverse Teams at Work: Capitalising on the Power of Diversity. Chicago: Irwin Professional Pub.

Glaser, B. G. \& Strauss, A. L. (1967). The Discovery of Grounded Theory: Strategies for Qualitative Research. New York: Aldine de Gruyter.

Goodman, J. (1983) 'How to get more smileage out of your life: Making sense of humour, then serving it', in McGhee, P. E. \& Goldstein, J. H. (eds.), Handbook of Humor Research, New York: Springer-Verlag, pp. 1-21.

Grimm, P. (2010). 'Social desirability bias', in Sheth, J. \& Malhotra, N. (eds.), Wiley International Encyclopedia of Marketing, Vol. 2, Chichester, West Sussex, UK: John Wiley \& Sons, pp. 258-259.

Haniff, N. Z. (1985). 'Toward a native anthropology: Methodological notes on a study of successful Caribbean women by an insider'. Anthropology and Humanism 10 (4), pp. 107113.

Henry, V. E. (1995). 'The police officer as survivor: Death confrontations and the police subculture'. Behavioural Science and the Law 13 (1), pp. 93-112.

Henry, V. E. (2004). Death Work: Police, Trauma, and the Psychology of Survival. New York: Oxford University Press.

Holmes, J. \& Marra, M. (2002). 'Having a laugh at work: How humour contributes to workplace culture'. Journal of Pragmatics 34, pp. 1683-1710.

Hudson, K. M. (2001). 'Transforming a conservative company one laugh at a time'. Harvard Business Review 79 (7), pp. 45-53.

Hughes, M.K. (2002). 'Through the looking glass: Racial jokes, social context, and the reasonable person in hostile work environment analysis'. Southern California Law Review 76, p. 1437.

Johnston, R. (1990). 'Humour: A preventive health strategy'. International Journal for the Advancement of Counselling 13 (3), pp. 257-265.

Karlsson, I. \& Christianson, S. A. (2003). The phenomenology of traumatic experiences in police work. Policing: An International Journal of Police Strategies and Management 26 (3), pp. 419-438.

Klein, A. (1998). The Courage to Laugh: Humour, Hope, and Healing in the Face of Death and Dying. New York: Penguin.

Kreiner, G. E., Ashforth, B. E. \& Sluss, D. M. (2006). 'Identity dynamics in occupational dirty work: Integrating social identity and system justification perspectives'. Organisation Science 17 (5), pp. 619-636.

Kuhlman, T. (1988). 'Gallows humour for a scaffold setting: Managing aggressive patients in a 
maximum security forensic unit'. Hospital and Community Psychiatry 39 (10), pp. 10851090.

Lampert, M. D. \& Ervin-Tripp, S. M. (2006). 'Risky laughter: Teasing and self-directed joking among male and female friends'. Journal of Pragmatics 38(1), pp. 51-72.

Lynch, O. (2010). 'Cooking with humor: In-group humor as social organization'. Humor: International Journal of Humor Research 23(2), pp. 127-159.

Mack, N., Woodsong, C., MacQueen, K. N., Guest, G. \& Namey, E. (2005). Qualitative Research Methods: A Data Collector's Field Guide. Research Triangle Park, North Carolina: Family Health International.

Martin, R. A. (2007). The Psychology of Humor: An Integrative Approach. Burlington, MA: Elsevier.

Meyer, J. C. (1997). 'Humour in member narratives: United and dividing at work'. Western Journal of Communications 61 (2), pp. 188-208.

McCarroll, J. E., Ursano, R. J., Wright, K. M. \& Fullerton, C. S. (1993). 'Handling of bodies after violent death: Strategies for coping'. American Journal of Orthopsychiatry 63 (2), 209-214.

McGhee, P. (2010). Humor as Survival Training for a Stressed-out World: The 7 Humor Habits Program. Bloomington, IN: Author House.

Morreall, J. (2008). 'Applications of humour: Health, the workplace and education', in Raskin, V. (ed.), The Primer of Humour Research, Berlin: Mouton de Gruyter, pp. 449-478.

Morreall, J. (2009). Comic Relief: A Comprehensive Philosophy of Humour. West Sussex: WileyBlackwell.

Neimeyer, R. A. (2001). Meaning Reconstruction and the Experience of Loss. Washington, DC: American Psychological Association.

Nijholt, A. (2004). 'Observations on humorous act construction'. Paper presented at the $17^{\text {th }}$ European Meeting on Cybernetics and Systems Research (EMCSR 2004). University of Vienna, Austria, 13-16 April.

O’Toole, P. \& Were, P. (2008). 'Observing places: Using space and material culture in qualitative research'. Qualitative Research 8 (5), pp. 616-634.

Patton, M. (1990). Qualitative Evaluation and Research Methods. Newbury Park, CA: Sage Publications.

Plester, B. \& Orams, M. (2008). 'Send in the clowns: The role of the joker in three New Zealand IT companies'. Humor: International Journal of Humor Research 21 (3), pp. 253-281.

Plester, B. A. \& Sayers, J. (2007). "Taking the piss": Functions of banter in the IT industry". Humor: International Journal of Humor Research 20 (2), pp. 157-187.

Porcu, L. (2005). 'Fishy business: Humor in a Sardinian fish market'. Humor: International Journal of Humor Research 18 (1), pp. 69-102.

Robinson, D. T. \& Smith-Lovin, L. (2001). 'Getting a laugh: Gender, status, and humour in task discussions'. Social Forces 80 (1), pp. 123-158.

Romero, E. J. \& Cruthirds, K. W. (2006). 'The use of humour in the workplace'. The Academy of Management Perspectives 20 (2), pp. 58-69.

Romero, E. J. \& Pescosolido, E. (2008). 'Humour and group effectiveness'. Human Relations 61 (3), pp. 395-418.

Saroglou, V. \& Anciaux, L. (2004). 'Liking sick humor: Coping styles and religion as predictors'. Humor: International Journal of Humor Research 17 (3), pp. 257-277.

Schnurr, S. (2008). 'Surviving in a man's world with a sense of humour: An analysis of women 
leaders' use of humour at work'. Leadership 4 (3), pp. 299-319.

Shank, G. D. (2006). Qualitative Research: A Personal Skills Approach. Columbus, OH: Pearson. Stroebe, M. \& Schut, H. (1999). 'The dual process model of coping with bereavement: Rationale and description'. Death Studies 23 (3), pp. 197-224.

Taylor, P. \& Bain, P. (2003). 'Subterranean worksick blues: Humour as subversion in two call centres. Organisation Studies 24 (9), pp. 1487-1509.

Thorson, J. A. (1993). 'Have you ever seen a hearse go by? Some thoughts on gallows humor'. Journal of American Culture 16 (2), pp. 17-24.

Tracy, S.J. \& Scott, C. (2006). 'Sexuality, masculinity, and taint management among firefighters and correctional officers: Getting down and dirty with "America's heroes" and the "Scum of law enforcement". Management Communication Quarterly 20 (6), pp. 6-36.

Triezenberg, K. (2004). 'Humour enhancers in the study of humorous literature'. Humor: International Journal of Humor Research 17 (4), pp. 411-418.

Vera, D. \& Crossan, M. (2005). 'Improvisation and innovative performance in teams'. Organisation Science 16 (3), pp. 203-224.

Vinton, K. L. (1989). 'Humour in the workplace: It is more than telling jokes'. Small Group Research 20 (2), pp. 151-166.

Wallinger, L. M. (1997). 'Don't smile before Christmas: The role of humour in education'. NASSP Bulletin 81 (589), pp. 27-34.

Weick, K. E. (1995). Sensemaking in Organisations. Thousand Oaks, CA: Sage Publications.

Westwood, R. (2004). 'Comic relief: Subversion and catharsis in organisational comedic theatre'. Organisation Studies 25 (5), pp. 775-795.

Westwood, R. I. \& Johnston, A. (2012). 'Reclaiming authentic selves: Control, resistive humour and identity work in the office. Organisation 19 (6), pp. 787-808.

Westwood, R. I. \& Johnston, A. (2013). 'Humor in organisation: From function to resistance'. Humor: International Journal of Humor Research 26 (2), pp. 219-247.

Westwood, R. \& Rhodes, C. (2007). 'Humour and the study of organisations', in Westwood, R. \& Rhodes, C. (eds.), Humour, Work and Organisation, London: Routledge, pp. 1-13.

Woody, R. H. (2005). 'The police culture: Research implications for psychological services'. Professional Psychology: Research and Practice 36 (5), pp. 525-529. 